Brit. Heart f., 1968, 30, 436.

\title{
Subclavian Artery Aneurysm and Idiopathic Cystic Medionecrosis
}

\author{
VASIL PERSAUD \\ From the Department of Pathology, University of the West Indies, Kingston 7, famaica
}

Non-traumatic aneurysms of the subclavian artery are rare. The reported cases have been due to compression from cervical ribs (Steinberg, 1964), syphilis (Muller, 1935; Daniel, 1951), atherosclerosis (McCallen and Schaff, 1956; Richards and Elliott, 1957; Björk, 1965), contiguous tuberculous lesions (Moloney, 1955; Hara and Bransford, 1963), and congenital defects in the arterial wall (Perry and Massey, 1953; Dobbins, 1961). There appears to be no previously reported case of aneurysm of the subclavian artery due to idiopathic cystic medionecrosis. An example of this was recently encountered at the University Hospital of the West Indies in a 22-year-old Negress. The findings in this patient form the basis of this report.

\section{Case Report}

A 22-year-old Negress attended the University Hospital of the West Indies on June 18, 1966, complaining of a lump in the left side of her neck which had been present from childhood. The swelling was pulsatile, had always been fairly constant in size, and was painless. She also experienced some numbness in the left hand over the past two months. There was no family history of Marfan's syndrome.

On examination, there was a round, smooth, pulsatile swelling, the size of a cherry, in the root of the neck on the left side. The brachial and the radial pulses in each arm were present and of equal volume. Her blood pressure was $130 / 90 \mathrm{~mm}$. Hg. A harsh systolic murmur was heard over the praecordium, maximal in the second left intercostal space. There were no stigmata of Marfan's syndrome.

Investigations. $\mathrm{Hb} 12.9 \mathrm{~g} . / 100 \mathrm{ml}$; total serum cholesterol $173 \mathrm{mg} . / 100 \mathrm{ml}$. Serological tests for syphilis were negative. A chest $x$-ray film showed no abnormality. A percutaneous transfemoral selective arteriogram showed a fusiform aneurysm of the left subclavian artery (Fig. 1).

At operation, a thin-walled fusiform aneurysm, $8 \mathrm{~cm}$. in diameter, involving the middle third of the left subclavian artery, was noted. The artery distal to the aneurysm was slightly larger in diameter than the proximal segment. The aneurysm was resected and a plastic graft $^{\star}$ inserted. The left radial pulse was palpable immediately after the insertion of the graft. The patient's post-operative course was uneventful, but at the time of discharge from hospital, the left radial pulse could not be felt. Three months later, the left radial pulse was still not palpable, but she was symptomless.

Pathological findings. The specimen was an ovalshaped sac, $8 \mathrm{~cm}$. in diameter. On opening the sac, the intimal surface was roughened on account of slightly raised grey areas of fibrosis in the smooth yellowishwhite lining. A striking feature was the extreme thinness of the wall, particularly when compared with a transverse section of subclavian artery from a control patient of similar age and sex (Fig. 2).

Histology. Paraffin-embedded, haematoxylin-eosin stained preparations showed patchy intimal thickening due to proliferation of fine collagen fibres separated by pale myxomatous tissue. The media was thin in comparison with the intima and the adventitia. The elastic laminae were separated by irregular cystic spaces containing basophilic amorphous material staining positively for connective tissue mucin with the Alcian Blue preparation (Fig. 3).

There was marked fragmentation and destruction of the elastic tissue fibres (Fig. 4). The vasa vasorum showed prominent subendothelial muscle hypertrophy, with narrowing of the lumens. There was no evidence of atheroma or a syphilitic arteritis.

\section{Discussion}

Since the original description by Gsell (1928) and Erdheim (1929), idiopathic cystic medionecrosis has been regarded as an important factor in producing weakness of the wall of the aorta. Medionecrosis has been observed under four circumstances: (a) in patients with dissecting aneurysms of the aorta (Gore, 1953); (b) in patients with Marfan's syndrome (Baer, Taussig, and Oppenheimer, 1942); (c) in "normal" aortas (Rottino, 1939); (d) in 436 


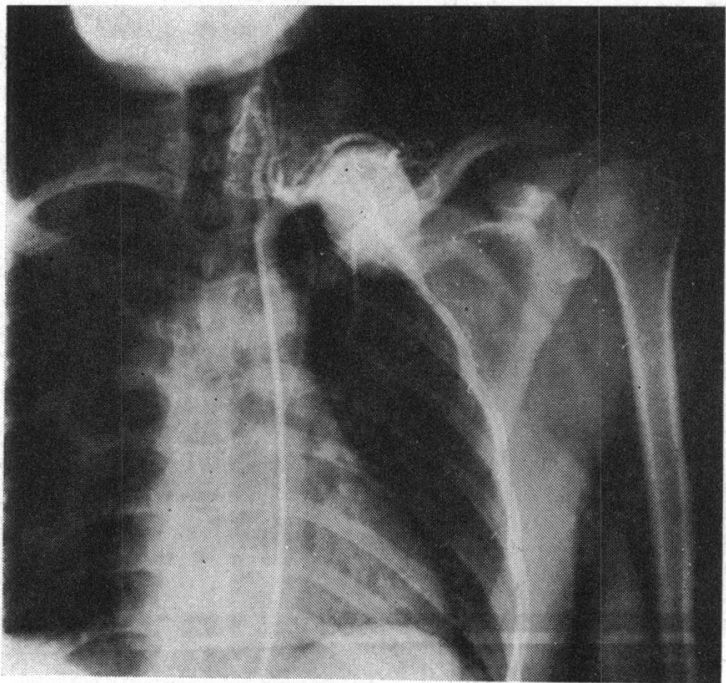

FIG. 1.-Pre-operative left sublcavian arteriogram showing a fusiform aneurysm of the mid-portion of the artery.

patients with rupture of the aorta due to thinning (Hayes and Woo-Ming, 1965).

Recently, one additional manifestation of medionecrosis has been recognized: the production of localized aneurysms in patients with or without features of Marfan's syndrome. Zeppa and Womack (1963) described a case of localized

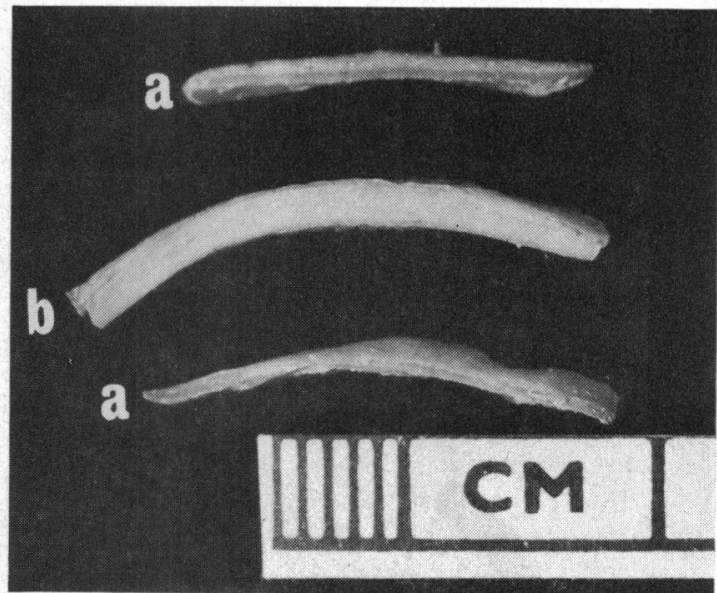

Fig. 2.-Transverse sections of the wall of the aneurysm (a) compared with a section of normal left subclavian artery from a patient of same age and sex (b).

aneurysm of the hepatic artery, caused by medionecrosis, in a 51-year-old woman. All other reports, however, have dealt with aneurysms confined to the thoracic aorta. Mattison and Cluff (1956) reviewed 5 previously reported cases and described one patient with fusiform aneurysm of the ascending aorta associated with cystic medionecrosis, the

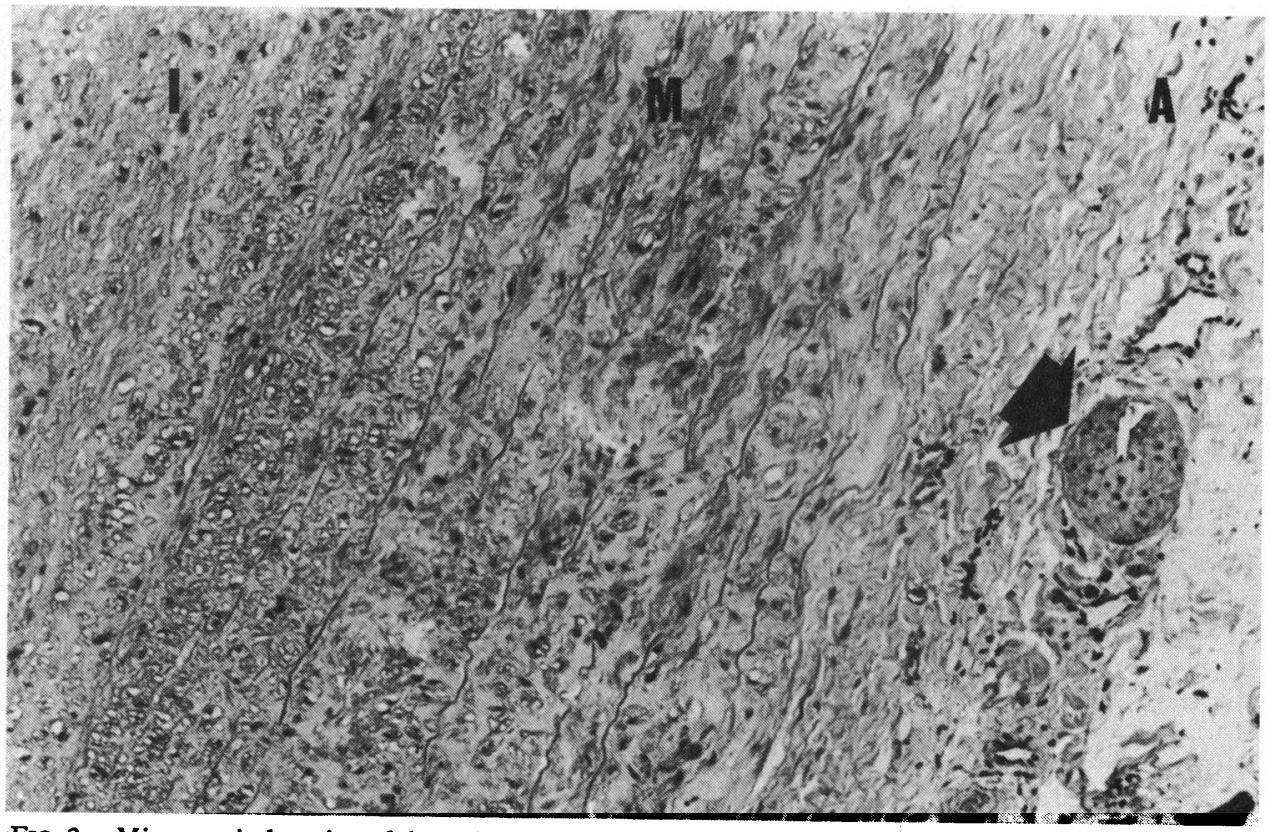
FIG. 3. - Microscopical section of the wall of the aneurysm showing pale, irregular cystic spaces in the media.
Note the thickened vasa vasorum (arrow). (H. and E. $\times 168)$. I, intima; M, media; and A, adventitia. 


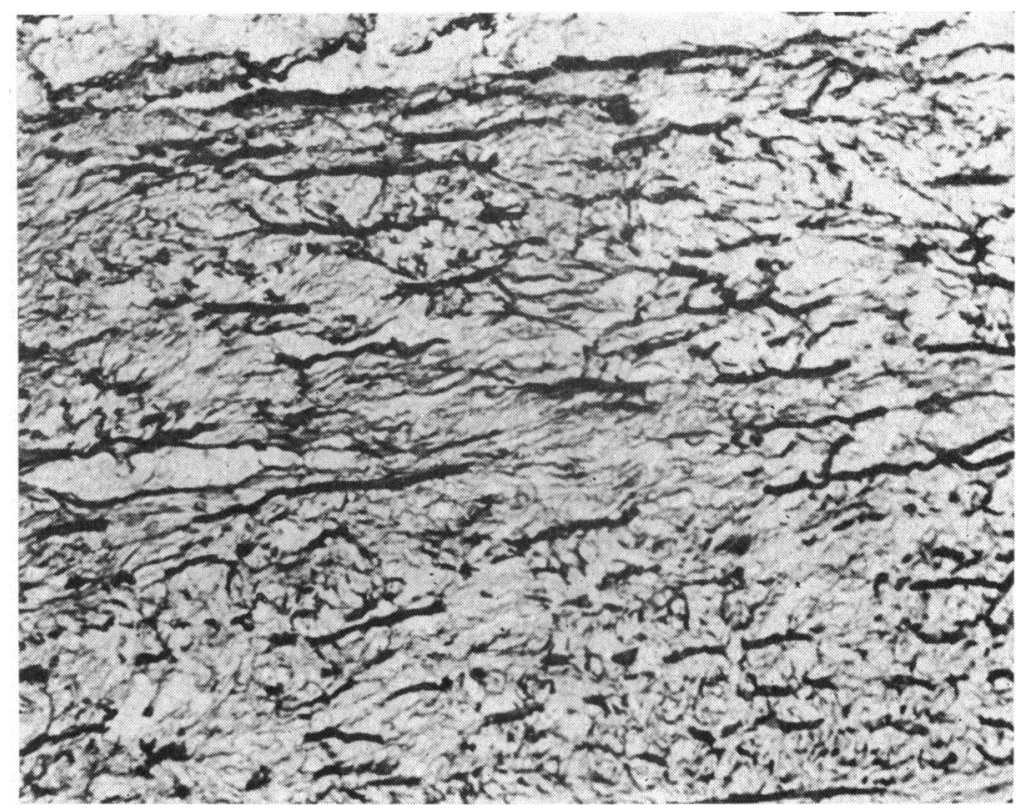

Fig. 4.-Fragmentation and destruction of the elastic laminae. (Elastic stain. $\times 415$ ).

first diagnosed during life. None of the patients demonstrated any stigmata of Marfan's syndrome. Bahnson and Nelson (1956) reported 5 cases of localized aneurysms of the thoracic aorta due to cystic medionecrosis in patients without features of Marfan's syndrome. The ages of the patients ranged from 31 to 49 years.

All the aneurysms, which were surgically treated, involved the ascending aorta except one where the aneurysm was situated in the distal aortic arch beyond the origin of the common carotid artery.

In a recent study of aortic aneurysms in Jamaica, dissecting aneurysms accounted for 26 per cent of 91 cases. All these were in Negroes, and cystic medionecrosis was the major underlying cause (Talerman, Hayes, and Lindo, 1967). Radiologically, aortic dilatation was detected frequently in a rural Jamaican population, accounting for about 8 per cent of over 2000 subjects (Stuart et al., 1962). Stuart suggested that medionecrosis might be an important aetiological factor, amongst others. If this is true, aneurysms due to cystic medionecrosis might be expected to occur in arteries other than the aorta. The present case would be an example of this.

Cystic medionecrosis occurring in the aorta in the case described here cannot be excluded, though aortic dilatation was neither observed radiologically nor at the time of operation. However, in view of the thickened vasa vasorum, the localized cystic medionecrosis may have been due to anoxia, as suggested by Erdheim (1929).

Post-stenotic dilatation due to pressure from a cervical rib or an abnormal first rib is known to occur (Steinberg, 1964). A similar change due to pressure from hypertrophied scalenus anterior muscle has also been mentioned (Wickham and Martin, 1962). In this patient, a thickened scalenus anterior muscle was found, but it is difficult to say whether this was a result or a cause of the aneurysm. The patient had no abnormal ribs.

The absence of the left radial pulse at the time of discharge from hospital was unexpected, since it was palpable immediately after the operation. It could be argued that this was an example of the Takayashu's syndrome, but the presence of radial pulses before operation, and the absence of any histological evidence of inflammation exclude this possibility. Presumably, the absence of the left radial pulse was due to thrombosis at the operation site.

\section{Summary}

The clinical, radiological, and pathological findings in a case of localized aneurysm of the left subclavian artery due to cystic medionecrosis are presented. The patient was a 22-year-old Negress with no stigmata of Marfan's syndrome. The aneurysm was treated successfully by resection and insertion of a Dacron graft. The pathogenesis 
of the aneurysm is briefly discussed. A search of the published material has failed to reveal any such case previously reported.

I wish to thank Dr E. M. Bateson, consultant radiologist, for his kind permission to use the arteriogram of this patient, and Dr. J. A. Hayes, for criticizing the manuscript.

\section{References}

Baer, R. W., Taussig, H. B., and Oppenheimer, E. H.(1942). Congenital aneurysmal dilatation of the aorta associated with arachnodactyly. Bull. Fohns Hopk. Hosp., 72, 309.

Bahnson, H. T., and Nelson, A. R. (1956). Cystic medial necrosis as a cause of localized aortic aneurysms amenable to surgical treatment. Ann. Surg., 144, 519.

Björk, V. O. (1965). Aneurysm and occlusion of the right subclavian artery. Acta chir. scand., Suppl., 356, 103.

Daniel, R. A. (1951). Syphilitic aneurysm of the subclavian artery. Ann. Surg., 134, 251.

Dobbins, W. O. (1961). Bilateral, calcified subclavian arterial aneurysms in a young adult male. New Engl. f.Med., 265, 537.

Erdheim, J. (1929). Medionecrosis aortae idiopathica. Virchows Arch. path. Anat., 273, 454.

Gore, I. (1953). Dissecting aneurysms of the aorta in persons under forty years of age. Arch. Path., 55, 1.

Gsell, D. (1928). Wandnerkrosen der Aorta als selbständige Erkrankung und ihre Beziehung zur Spontanruptur. Virchows Arch. path. Anat., 270, 1.

Hara, M., and Bransford, R. M. (1963). Aneurysm of the subclavian artery associated with contiguous pulmonary tuberculosis. f. thorac. cardiovasc. Surg., 46, 256.
Hayes, J. A., and Woo-Ming, M. O. (1965). Diffuse cystic medionecrosis and aortic thinning: rupture at operation in a young man with a patent ductus arteriosus. Dis. Chest, 48, 645.

McCallen, A. M., and Schaff, B. (1956). Aneurysm of an anomalous right subclavian artery. Radiology, 66, 561.

Mattison, W. E., and Cluff, L. E. (1956). Fusiform aneurysm of the ascending aorta associated with medionecrosis. Bull. Fohns. Hopk. Hosp., 98, 309.

Moloney, G. E. (1955). Excision of an aneurysm of the right subclavian artery: case history and discussion. Brit. $\mathcal{F}$. Surg., 43, 94.

Muller, G. P. (1935). Subclavian aneurism. Ann. Surg., $101,568$.

Perry, S. P., and Massey, C. W. (1953). Bilateral aneurysms of the subclavian and axillary arteries. Report of a case. Radiology, 61, 53.

Richards, W. C. D., and Elliott, C. E. (1957). Aneurysm of an anomalous right subclavian artery. Brit. Heart F., 19, 141.

Rottino, A. (1939). Medial degeneration of the aortaA study of 210 routine autopsy specimens by a serial block method. Arch. Path., 8, 377.

Steinberg, I. (1964). Poststenotic dilatation (aneurysm) of the subclavian artery associated with cervical rib. Amer. F. Roentgenol., 92, 1328.

Stuart, K. L., Miall, W. E., Tulloch, J. A., and Chistian, D. E. (1962). Dilatation and unfolding of the aorta in a Jamaican population. Brit. Heart f., 24, 455.

Talerman, A., Hayes, J. A., and Lindo, V. E. R. A. (1967). Aortic aneurysms in Jamaica. To be published.

Wickham, J. E. A., and Martin, P. (1962). Aneurysm of the subclavian artery in association with cervical abnormality. Brit. F. Surg., 50, 205.

Zeppa, R., and Womack, N. A. (1963). Medial degeneration and aneurysm of the hepatic artery. Arch. Surg., 86, 252. 